Rhode Island College

Digital Commons @ RIC

$1-1-2011$

\title{
The Impact of Neonatal ICU Single Family Rooms on Select Developmental Outcomes
}

Lynda M. D'Alessio

Rhode Island College

Follow this and additional works at: https://digitalcommons.ric.edu/etd

Part of the Public Health and Community Nursing Commons

\section{Recommended Citation}

D'Alessio, Lynda M., "The Impact of Neonatal ICU Single Family Rooms on Select Developmental Outcomes" (2011). Master's Theses, Dissertations, Graduate Research and Major Papers Overview. 204. https://digitalcommons.ric.edu/etd/204

This Major Paper is brought to you for free and open access by the Master's Theses, Dissertations, Graduate Research and Major Papers at Digital Commons @ RIC. It has been accepted for inclusion in Master's Theses, Dissertations, Graduate Research and Major Papers Overview by an authorized administrator of Digital Commons @ RIC. For more information, please contact digitalcommons@ric.edu. 


\section{THE IMPACT OF NEONATAL ICU SINGLE FAMILY ROOMS ON SELECT DEVELOPMENTAL OUTCOMES}

A Major Paper Presented

By

Lynda M. D'Alessio

Approved:

Committee Chairperson

Committee Members
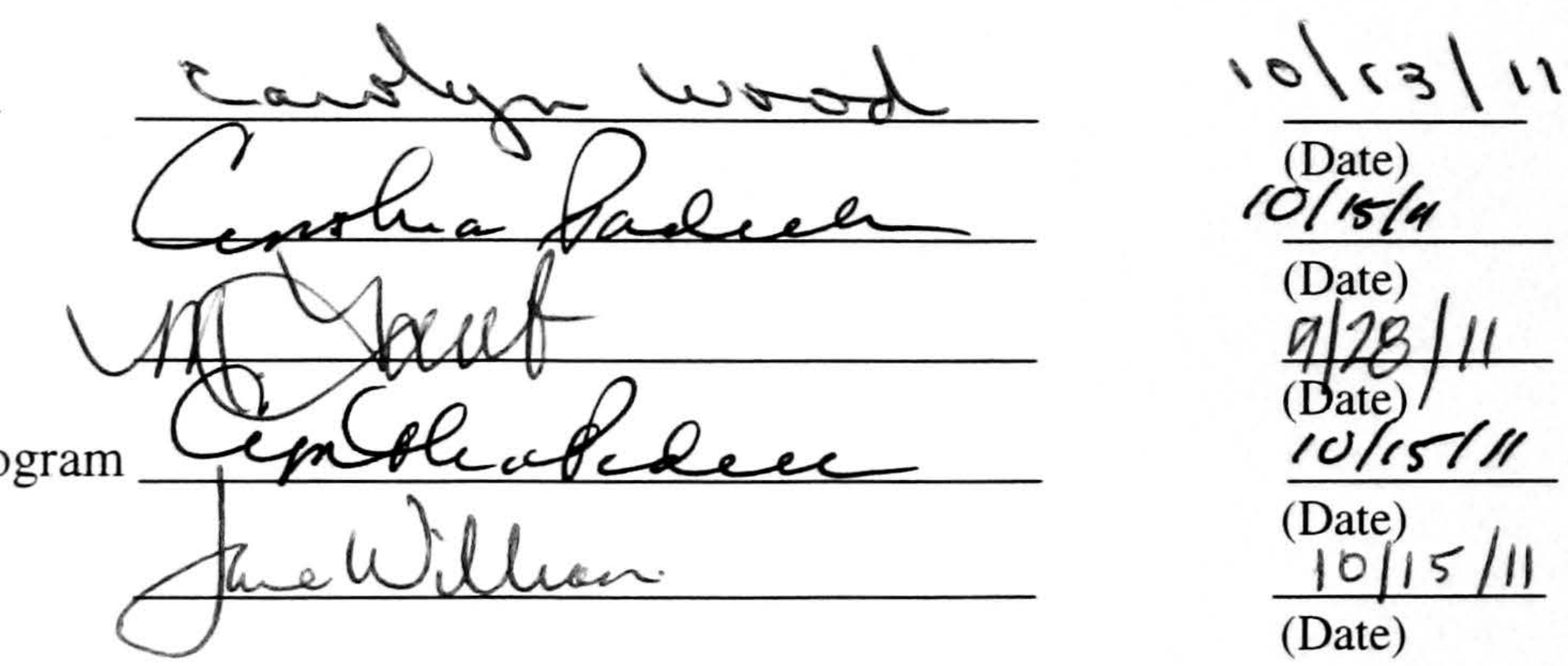
THE IMPACT OF NEONATAL ICU SINGLE

FAMILY ROOMS ON SELECT DEVELOPMENTAL OUTCOMES

by

Lynda M. D’Alessio

\begin{abstract}
A Major Paper Submitted in Partial Fulfillment
Of the Requirements for the Degree of

Master of Science in Nursing

in
\end{abstract}

The School of Nursing

Rhode Island College 


\begin{abstract}
The purpose of this study was to determine if there is a weight gain benefit and earlier achievement to full feedings in the single family room NICU design compared to the multi-bed NICU design.

A retrospective chart review of infants less than 1000 grams born during a three month time frame in both the multi-bed unit and single family unit was conducted. The study compared average daily weight gain and achievement to full feedings in the multi-bed unit and single family room unit. Findings concluded there was a slight difference in the average daily weight gain and achievement to full feedings occurred several days earlier in the single family room unit.
\end{abstract}

In the single family unit the advanced practice nurses are able to promote a family-centered environment by encouraging rooming in, Kangaroo care, and breastfeeding, all of which were nearly impossible for the parents to accomplish in the multi-bed unit due to lack of space and privacy. 


\section{Acknowledgements}

I would like to extend a sincere thanks to the many people who have supported me throughout my studies. First I would like to thank my family, especially my husband Butch, and children Nicholas, Kaitlyn, and Kristina for all their love and support.

I would also like to thank my Care New England coworkers for their support, encouragement, and patience with me during project completion.

Finally, I would like to thank both Dr. Cindy Padula and Dr. Carolyn Wood for their enthusiasm, knowledge, and guidance throughout this endeavor; I could not have done it without them! 
Table of Contents

Table of Contents.

Page

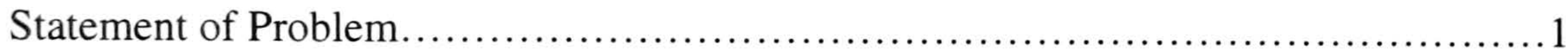

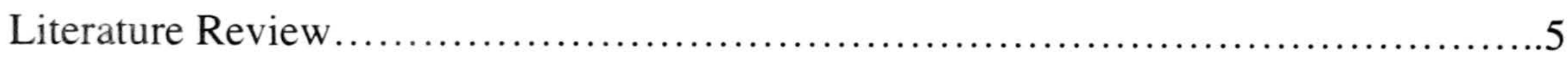

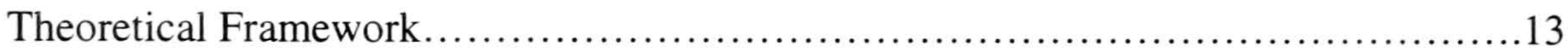

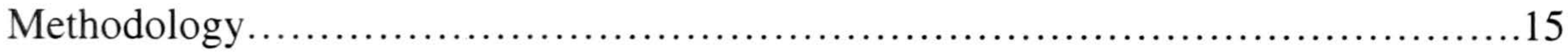

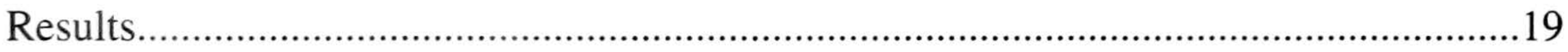

Summary and Conclusion.............................................. 23

Recommendations and Implications for Nursing Practice........................................25

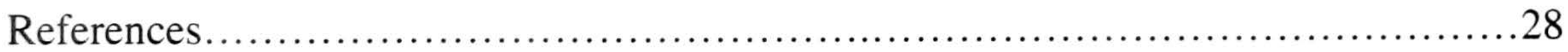

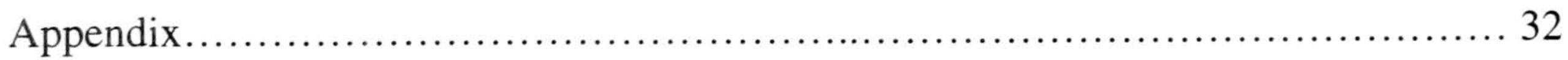


The Impact of Neonatal ICU Single Family Rooms on Select Developmental Outcomes

\section{Statement of the Problem}

A preterm birth is any birth prior to 37 weeks gestation (Goldenberg, Culhane, Iams, \& Romero, 2008). Each year more than 500,000 babies are born prematurely in the United States (US) and over 13 million babies are born prematurely worldwide (March of Dimes, 2009). There is no one reason for a premature delivery; however, several risk factors have been identified including low socioeconomic status, low prepregnancy weight, inadequate weight gain during pregnancy, alcohol consumption, smoking, multiple gestation, uterine and cervical insufficiency, and a history of infertility (Centers for Disease Control [CDC], 2009).

Rhode Island (RI) has the highest rate of prematurity in New England at 12.1\% (Freyer, 2009). According to the Rhode Island Department of Health (RIDOH) Kids Count Factbook (2009), women under the age of 20 and over the age of 35 have the highest preterm birth rates in our state, with the highest rate in the 12-14 year old age group.

Nationally, every year an average of $\$ 10.2$ billion dollars is spent on newborn care; of those births, $11 \%$ of deliveries each year are preterm, and $\$ 6$ billion (57\% of the total monies spent on newborns) is spent to care for these premature infants (St. John, Nelson, Oliver, Bishnoi, \& Goldenberg, 2000). The Institute of Medicine (IOM) ("Preterm Birth", 2006) estimated that the average first year medical costs are 10 times greater for preterm infants than for full term infants. The annual societal economic burden associated with preterm birth in the US was $\$ 26.2$ billion in 2005 or $\$ 51,600$ per infant born preterm (IOM).

According to the National Institute of Nursing Research (2007), preterm infants have a higher mortality rate, as well as higher rates of health concerns and developmental problems after birth. While in 
the NICU, such problems include respiratory issues, bleeding in the brain, infection, and death of part of the gastrointestinal tract (Belfort, 2006). After discharge, preterm infants are more likely to experience long term motor, cognitive, sensory, behavioral, emotional, and learning deficits ("Findings From", 2007). According to Blackmore and Rowley (2009), the CDC concurs with the preceding report and lists potential additional lifelong problems for premature infants such as cerebral palsy, respiratory and/or breathing problems, feeding and digestive problems, and vision and hearing loss, which, depending upon the severity, may necessitate a longer or more frequent hospitalization.

In 2007, the Consensus Committee to develop Recommended Standards for Newborn ICU Design (White, 2007) published their recommendations to improve the NICU environment. One of the suggestions was flexibility in lighting so that infants at different stages of development and at various times of the day can be accommodated. This recommendation implied that infants greater than 28 weeks gestation benefited from cycled lighting and an infant should be able to be assessed without disturbing others. According to Floyd (2005), continuous bright lighting reduces growth and increases physiological instability. As for the acoustic environment, there should be minimal noise. Walsh, McCullough, and White (2006) noted that the late 1990's brought about evidence that the sensory environment of the NICU had harmful effects on preterm infants. Floyd (2005) stated that although NICU noise had not been proven to cause hearing loss, a link had been established between exposure to constant room noise and loss in frequency and pattern discrimination necessary to understand the spoken word.

Women and Infants Hospital in Providence, RI is a tertiary care center and the only Level III NICU for RI, nearby South Eastern Massachusetts, and Eastern Connecticut. In 1986, Women and Infants opened its new multi-bed open bay unit that was built to accommodate approximately 41 infants; however, soon 
after opening, the average daily census was greater than 65 infants. This multi-bed, open bay unit consisted of five bays; four of the bays were for Level III infants, which are infants that require ventilatory support, and the fifth bay, which was in a separate area, was for those infants feeding, growing, and preparing for discharge. On most days, there were 12-15 infants positioned side by side along three walls of any given open bay. Nursing care was provided in a community-based atmosphere, with nurses responsible for their own assignments, but often assisting another nurse's patient if he/she was not readily available. These bays were loud and typically consisted of several nurses, parents, physicians, respiratory therapists, and ancillary staff simultaneously talking and caring for infants. Space and parental involvement with care was extremely limited; hence, there was a lack of privacy for both breastfeeding and kangaroo care. In addition, during multidisciplinary rounds, parents could not be in the bay for several hours at a time; instead, they would wait outside the NICU doors for their next chance to visit with their baby.

In September 2009, Women and Infants Hospital opened the largest single-family room NICU in the nation. It spreads over 50,000 square feet and is two stories high. This unit has 80 beds available; 70 of them for singletons and 10 rooms are designated to accommodate families of multiples. Each family has their own room equipped with a couch that converts to a bed, private bathroom, supply closet, and plenty of room for family members and privacy. Parents are now encouraged to stay during multidisciplinary rounds, care for their infant, and participate in decisions regarding their infants care and treatment. Women and Infants Hospital believes this new design is conducive to developmental care because it allows for the sound, light, and temperature to be tailored to each infant's individual needs as well as increased privacy for breastfeeding and kangaroo care. 
The purpose of this study was to determine if there is a weight gain benefit and earlier achievement to full feedings in the single family room NICU room compared to the multi-bed unit. 


\section{Literature Review}

A literature review was conducted in several databases including CINAHL, Medline, Pub Med, Cochrane Library, and OVID. This review was conducted over a three-month time span. Key words used to conduct this review included NICU, design, neonatal, outcomes, development, full feedings, nutrition, open-bay, single room, positive, feedings, and family.

Harrell and Moon (2008) conducted an architectural review to determine what design is most effective for the development of the premature infant by reviewing the concept of family centered care, the multi-bed vs. single family room environment, and the overall NICU environment. They reviewed the history of the NICU, which started as an open bay ward in the 1960's to the late 1980's, when there was an increased percentage of "micropremies", infants born at 23-25 weeks gestation. At that time, both the American College of Obstetrics and Gynecology (ACOG) and the American Academy of Pediatrics (AAP) agreed that the modern NICU should make privacy a priority for skin-to-skin contact, breastfeeding, and increased participation by the family. They believed that new units should be designed to have visual and audible controls, greater access to natural light, enhanced air-handling systems including draft elimination, air filtration, and separate temperature control.

Harrell and Moon (2008) believed that advantages unique to the premature infant in the single family room design include increased control of the environment, which more often than not plays a part in the development of this population. Although more studies are needed, lighting effects on the infant and care providers are known to be significant by reducing fatigue and maintaining their circadian balance. As for noise control, Harrell and Moon also stated that reducing the environmental, sound-producing factors is important for the development of premature infants, and further steps need to be taken for noise reduction in 
all patient areas. The single family room design is also the most effective way of controlling infection. Harrell and Moon believed that evidence-based design would only enhance the healing and growing environment of future premature infants, but more research is needed into the effects of the environment of premature infants.

White (2003) reviewed the literature and identified advantages, disadvantages, and strategies for success when adopting the individual room design concept. The advantages of individual rooms include each infant having the proper amount of lighting and sound appropriate to the developmental state, as well as increased privacy and accessibility for family. This environment has the potential to improve infant growth. In conclusion, White (2003) stated that an infant who needs a very controlled environment, whose mother is breastfeeding and/or rooming-in, and the terminally ill infant are examples of situations when a private room is beneficial. Other than those infants, or isolated incidences requiring privacy, the value of the concept for enhanced growth and development in the infants themselves remains unclear, and many caregivers are not convinced of the superiority of this concept. Hence, it appears that further study is needed to determine the potential impact of room design on specific outcomes in both the multi-bed unit and the single family room NICU setting.

Walsh, McCullough, and White (2006) developed a survey to determine the perceptions of 127 NICU nurses after they transitioned to a single family room NICU. The study also evaluated the impact of the single family room model on noise level and rates of catheter related bloodstream infections before and after the move to the single family room unit. The prior NICU setting was a 54-bed Level IIIC NICU, with 1100 admissions every year. The unit consisted of six multi-bed rooms, and was approximately 5,000 square feet. The new single family room design was a 61 bed Level IIIC NICU occupying over 61,000 square feet and 
had approximately 1200 admissions per year. This unit had 44 intensive care beds in 40 rooms, with four of the rooms designated for twins. The 40 rooms were divided into pods, each pod containing six to seven infants, and the pods separated off into single family rooms with natural lighting. These rooms were separated from the corridor by sliding glass doors with privacy curtains. Bedside monitors were connected to a central station, as well as remote monitors on the pod walls, to facilitate visualization of the alarms by the nursing staff. Nurses communicated with the central nursing station by telephone and contact ancillary staff via walkie-talkie.

Nine months after moving into the new unit, the NICU nursing staff were surveyed to determine their perception of the new NICU, including their preference, safety, communication, availability for help, and workload. The majority of nurses surveyed $63 \%(n=80)$ thought the single family room design was superior. When asked about the safety of the ventilated infants in the single family room setting, $65 \%$ $(n=83)$ responded they did not feel the single family room design was dangerous; however, many nurses preferred the multi-bed unit for ventilator dependent infants. Blood stream infections and noise levels were also compared in the Walsh study. The rate of catheter related blood stream infection was 10.1 per 1000 device days prior to the move (in the multi-bed unit). At nine months after the move to the single family room NICU, the rate was 3.3 per 1000 device days. The noise levels for both those receiving and not receiving continuous positive airway pressure were measured at the bedsides; the multi-bed unit levels measured at $63.3+2.1 \mathrm{~dB}$, compared to the single family room levels of $56+3.1 \mathrm{~dB}$. The CPAP device raised the sound levels in both areas to $70 \mathrm{~dB}$ and audio alarm levels were $65 \mathrm{~dB}$ at the infants head. Walsh et al. expressed that further research on the acute physiological changes of infants cared for in single family rooms is necessary. 
Milford, Zapalo, and Davis (2008) explored the process of transition from a multi-bed unit to an individual room design at Magee-Women's Hospital of the University of Pittsburg Medical Center. This undertaking allowed a team of staff and NICU-graduate families an opportunity to design a NICU with emphasis on family centered care and improved communication. Since this was a massive budget concern, the staff was charged with proposing a NICU design that would be functional for at least 15 years. They began by reviewing relevant literature to determine if the single family room was developmentally supportive and family centered, and to explore the sensory component of the single family room. The nursing staff also wanted to determine if there was evidence based information to support decreased sensory overload and increased growth and development as compared to the open-bay unit. They proposed, "An appropriate controlled environment decreases stress to the infant and supports the use of his energy for growth and development" (p.300). Their literature review concluded that the individual room environment has the potential to improve weight gain and initiation of earlier feedings.

The nurses expressed their preference to include the family in their multidisciplinary rounds, procedures, during change of shift report, and in emergencies. They also wanted to spend more quality time with the families without the noise from other distractions. Once they decided to move forward with the individual room project, a team was established consisting of architects, parents, representatives from administration, nursing, medical staff, environmental services, pharmacy, and others, as deemed necessary. After the new unit was built, staff was surveyed at six months, 12 months, and 24 months after the move into the new unit. All areas of staff satisfaction with the new design increased with the exception of noise and cleanliness. The unit began randomly monitoring monthly measurements of ambient noise, and the noise level was consistently less than $50 \mathrm{~dB}$, a recommended standard for NICU design. In addition, 
lighting was decreased in the individual rooms for 10 hours each night to support development of diurnal patterns.

Floyd (2005) described the challenges faced by Children's Hospital Los Angeles as this institution embarked on developing a new NICU design. Floyd stated that in the 1980's, concern about survival without disabilities came to the forefront; hence, developmental research emerged that created a focus on the preterm infants' environment during their first month of life. This research and its recommendations regarding light and noise control has influenced the design of today's NICU. Floyd referred to studies conducted by Mann (1986), Blackburn and Patterson (1992), and Brandon et al. (2002) which indicated that cycled light is beneficial, and continuous, bright lighting both reduces growth and increases physiological instability. Noise in a unit can also cause repeated apnea and bradycardia for a premature infant, especially when "exposed to normal adult activities in the NICU" (p.64). Floyd suggested that limiting exposure to adult noise can decrease the number of alarms caused by apnea and bradycardia that represent physiological compensation. Floyd also stated that providing developmental care (such as the care given in a single family room) that emphasizes the needs of each individual preterm infant results in earlier initiation of feedings and increased weight gain.

Cattaneo et al. (1998) conducted a randomized controlled trial in three tertiary and teaching hospitals that studied the effectiveness, feasibility, and acceptability of kangaroo care compared to conventional methods of care for premature infants weighing between 1000-1999 grams. Two of the hospitals in the study were able to accommodate the kangaroo care mothers in their own rooms, while the other hospital had the kangaroo care mothers four to a room, with privacy screens between them. The results indicated that the kangaroo care infants were breastfed more and showed a trend towards higher mean daily weight gain. 
Kangaroo care infants achieved discharge weight in a shorter time (11 days after enrollment) compared to those receiving conventional care (13 days after enrollment). Promotion of kangaroo may be an easier process in a single room unit and is an important factor in enhancing infant nutrition.

Hayakawa et al. (2003) described adequate nutrition as being "crucial" in the management of the extremely low birth weight infant because under nutrition during the early neonatal stage can "affect the growth of the central nervous system" (p.991).

Bloom et al. (2003) identified weight gain of the very low birth weight infant as an area of improvement. A study was conducted that collected weight gain statistics from several NICU's from January 1, 1997 to June 30, 1999 to determine if variation in common practices affected clinical outcomes. As the researchers were conducting the baseline assessment of several NICUs, they noted significant variations in weight gain and practice such as managing fluids and feedings along with ventilator support and the environment.

Bloom et al. (2003) concluded that choices made in practice that can affect outcomes and systems-ofcare are often driven by the past, or the way it has been done, and not by the needs of the patients and their families. They suggested that weight gain is a priority and their research identified areas of opportunity in the NICU to align their processes to facilitate increased weight gain for infants.

Pickler, Best, and Crosson (2009) believed that the process by which preterm infants attain feeding competence might be important to both their short and long-term neurological development. They conducted a longitudinal, non-experimental study to determine the effects of feeding on clinical outcomes. They concluded that those preterm infants with more oral feeding experiences achieved full feedings sooner, had a shorter length of stay, and had improved outcomes without having weight loss or a slower weight 
gain. A more structured feeding approach to feeding was also used, such as more opportunities to oral feed, which may facilitate an earlier transition from gavage to oral feedings. Pickler et al. also concluded that infant clues for readiness might be missed by caregivers moving in and out of the room, but might be assessed and taken advantage of in the single family room environment where parents can be more readily available to become familiar with feeding cues.

Ali, Sharma, Sharma, and Alam (2009) conducted a randomized controlled trial in which the efficacy of low birth weight premature infants' kangaroo care was compared to conventional care. They accomplished this by giving the infants skin-to-skin contact, in the upright position between their mothers' breasts, as soon as they became hemodynamically stable. The skin-to-skin contact was given for one hour increments at minimum, and several times a day. Of note, mothers were given front open gowns and placed in a private area for care. The control group infants were placed on a radiant warmer, incubator, or in an open crib in a heated room. The infants receiving kangaroo care gained approximately 9 grams more a day than those in the conventional setting, had a much lower rate of nosocomial sepsis and severe infection, and maintained higher breastfeeding rates.

Swift and Scholten (2009), utilizing a qualitative phenomenological research design, conducted interviews of nine sets of parents whose infants had feeding difficulties while in the NICU to determine the relevance, if any, to family centered care. "Mother's want their expertise to be recognized by the professionals caring for their infants and they want to be considered pivotal in the care of their children" (Spalding \& McKeever 1998, p. 240-241). Parents reported that they thought that their baby would follow a "normal" progression from gavage to bottle or breast resulting in weight gain. This progression was important to them because they often heard their baby was not going home until feedings were established; 
those who experienced a delay in the establishment of feedings described their NICU experience as frustrating. Sensitive staff members who spent time with the parents played an active part in encouraging them and encouraging parent-infant bonding. Fathers expressed their appreciation for being able to bottle feed their infant breast milk, but felt uncomfortable in the presence of breastfeeding mothers; they were not sure how or if they were accepted. The need for privacy of fathers to feed their babies is an important factor to consider in promoting infant nutrition. In conclusion, Swift and Scholten (2009) believed that mothers need to feel comfortable with breastfeeding their baby in the NICU environment, and fathers need to feel they are a part of the care of their infant without feeling uncomfortable. An additional room, permanent partition, or single family room environment for breastfeeding mothers could help resolve this conflict

Overall, all studies indicated there are several benefits to having single family rooms in the NICU. These include parents and families having the opportunity to provide kangaroo care, breastfeed, and stay with their infant without having to leave the room several times per day for multidisciplinary rounds, change of shift, or lack of space. As important, the single family room allows for the parents to be involved with multidisciplinary rounds and participate in the plan of care for their infant.

Next, Donabedian's theoretical framework will be presented as the framework used to guide this research. 


\section{Theoretical Framework}

The Donabedian Quality-of-Care framework (1988) has been widely used to examine health services and assess patient outcomes. According to Donabedian (2003), there are three approaches to assessing quality care: structure, process, and outcome, and all of which are interdependent. Kunkel, Rosenqvist, and Westerling (2007) noted that Donabedian's structure refers to the resources available for working towards a quality improvement; the structure is the prerequisite necessary to complete the process and outcomes. Examples of structure include time, money, staff, and material resources, such as the hospital building. For the purpose of this study, the structure is the new, single family room unit. The process describes how the structure is put into practice, for example the activities carried out by the health care providers for the benefit of the patient (Donabedian, 2003). Examples of process include diagnosis and treatment, collaboration between the multidisciplinary team, and improved culture. For the purpose of this study, the process is the delivery of care and increased parental involvement in the new, developmentally appropriate NICU environment. Donabedian (1988) described outcomes as being either technical or interpersonal. Technical outcomes encompass the physical and functional aspects of care, such as the management of chronic patients. Interpersonal outcomes encompass the "art" of medicine such as patient satisfaction with the care received or their perception of quality of life. Using this framework, the two outcomes are viewed as interdependent to each other; neither can be taken independently to evaluate for quality care. Donabedian stated that to monitor outcomes is to monitor performances, and performances are conditional on structure and process. He believes that no level of quality can be very satisfactory, as expectations of patients and providers are continually shifting upwards. 
The outcome is a direct result of the process and structure. Outcomes can be measured based on patient satisfaction, improvement in patient status, and increased patient/family knowledge (2003). For the purpose of this study, the outcome is the average daily weight gain and the number of days from birth to achievement of full feedings in the multi-bed unit versus the single family room NICU to determine whether the single family room improves the infants status by increasing the average daily weight gain and achieving full feedings earlier than those infants in the multi-bed unit.. 


\section{Methods}

\section{Purpose}

The purpose of this research study was to determine if a single family room NICU design directly impacts infant nutritional outcomes as measured by the average daily weight gain and achievement of full feedings for infants born less than 1000 grams.

\section{Research Question}

The research questions was: What is the impact of a multi-bed bay NICU vs. a single family room NICU on a premature infant's weight gain and achievement of full feedings in the hospital setting?

\section{Design}

This study employed a retrospective, two group, quasi-experimental design. The independent variable was the overall NICU design (multi-bed bays vs. single family rooms). The dependent variables were the premature infants' average daily weight gain and achievement of full feedings.

\section{Site and sample}

This study was conducted at Women \& Infants Hospital, more specifically, the NICU, and compared average daily weight gain and advancement to full feedings in the multi-bed care environment to the single family room environment. The multi-bed unit was located in the main hospital and officially closed in September 2009. The single family rooms are located in the newly constructed multi-story wing of the hospital, which opened in September 2009. 
All extremely low birth weight premature infants weighing less than 1,000 grams who were admitted to either the multi-bed NICU or single family room NICU for greater than two weeks during the three month study period were identified. This sample also included transports to Women \& Infants Hospital NICU within the first 24 hours of life from a regional Level II nursery. Infants excluded from this study were those with congenital anomalies requiring surgical intervention, infants with feeding intolerance requiring intervention, and multiples sharing the same room (for the single family room study only).

\section{Procedures}

Prior to beginning this study, approval was granted from the Woman \& Infants Hospital and the Rhode Island College Institutional Review Boards.

The admission information for both NICU cohorts was collected from the Unit Secretaries' Admission Log. The multi-bed NICU design Admission Log was reviewed for infants weighing less than 1000 grams from January 2009 to April 2009. The Admission Log provided the following information: name, medical record number, admission date, birth weight and multiple gestations (as applicable). The weight criteria for the single family NICU review was the same; however, admissions from January 2010 to April 2010 were evaluated for meeting study criteria. The Admissions Log information and electronic medical record documentation allowed for the simultaneous gathering of admission information and chart review. To maintain strict confidentiality, each infant eligible to be a study participant was assigned a number (beginning with the number one) which served as the infants' identifier. There were no names, medical record numbers, or personal health information recorded.

The electronic medical record review consisted of an analysis of the nutritional information record on the nursing flow sheets to determine when the infant achieved full feedings for greater than 72 hours. The 
discharge summary was reviewed to collect data related to surgical procedures, discharge date and discharge weight. This information was necessary for calculating the average daily weight gain.

\section{Measurement}

A data collection sheet was developed to collect demographic data such as the day of birth, discharge date, birth weight and discharge weight, average daily weight gain, the day of life that full feedings were achieved, and whether the feedings were maintained for greater than 72 hours (see Appendix 1).

Confidentiality was maintained by assigning a number in lieu of patient identifiers. The data collected were stored in a locked box to which only the investigator had access.

The average daily weight gain (ADWG) was calculated by collecting the birth weight, discharge weight, and the number of days that the infant was in the NICU before discharge to home or transfer. The difference between the discharge weight and admission weight was divided by the number of days alive to determine the average daily weight gain, as illustrated below.

ADWG=discharge weight-admission weight/number of days alive

The infants' average daily weight gain were added together and divided by the number of participants to determine the cohorts overall average daily weight gain.

\section{Overall $\mathrm{ADWG}=$ average daily weight gain/number of infants}

Achievement of full feedings (by gavage, bottle, or breast) was calculated by reviewing the nutritional information record of the nursing flow sheets. An infant was considered successfully advanced to full feedings if feedings were maintained for greater than 72 hours. This measurement was recorded in days, 
with day of life zero being the date of birth and the day of advancement to full feedings was the final day counted.

Achievement of full feedings (AFF) $=$ number of days between date of birth and date of advancement to full feedings

The infants' day of life full feedings were totaled and divided by the number of participants to determine the cohorts overall day of life of achievement of full feedings.

Overall AFF = total number of days between date of birth and date of advancement to full feedings/number of infants

Calculation accuracy was validated by calculating the information in Excel and double-checking the accuracy manually. As for the accuracy of days between date of birth and achievement of full feedings, a calendar was used to count each day in the month and the calculations were verified by conducting a recount

\section{Data Analysis}

Descriptive statistics were used to analyze both the average daily weight gain and advancement to full feedings. 


\section{Results}

From January-April 2009, there were 28 infants born weighing less than 1000 grams in the multi-bed unit NICU. Of those infants, four were excluded due to feeding issues requiring intervention, one required a surgical procedure, and four passed away; therefore, 19 infants qualified for inclusion in the multi-bed NICU cohort.

From January-April 2010, there were 27 infants born less than 1000 grams in the single family room NICU. Of those infants, three were excluded due to feeding issues requiring intervention, one required a surgical procedure, four were excluded because there were two sets of twins, and six infants passed away; therefore, 13 infants qualified for inclusion in the single bed NICU cohort.

Table 1 represents the average daily weight gain for the 19 infants from the multi-bed unit cohort.

\section{Table 1}

\section{Multi-Bed Unit Average Daily Weight Gain}

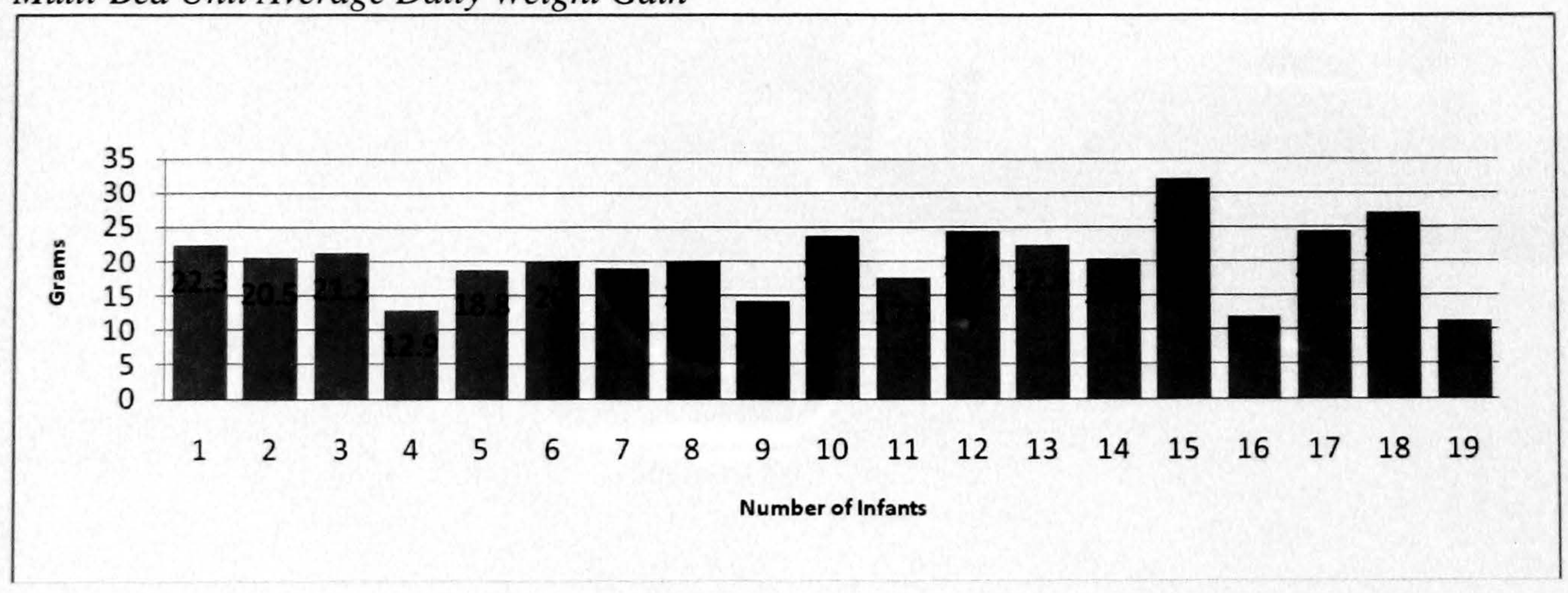

The average daily weight gain for the 19 infants in the multi-bed unit cohort was 20.0 grams/day. 
Table 2 displays the average daily weight gain for the thirteen infants from the single family room cohort. The average daily weight gain was 23.4 grams/day, with a range of 18.6 grams/day to 28.5 grams/day. This cohort reflected consistency with weight gain and less variability than in the multibed unit cohort.

Table 2

\section{Single Family Room Average Daily Weight Gain}

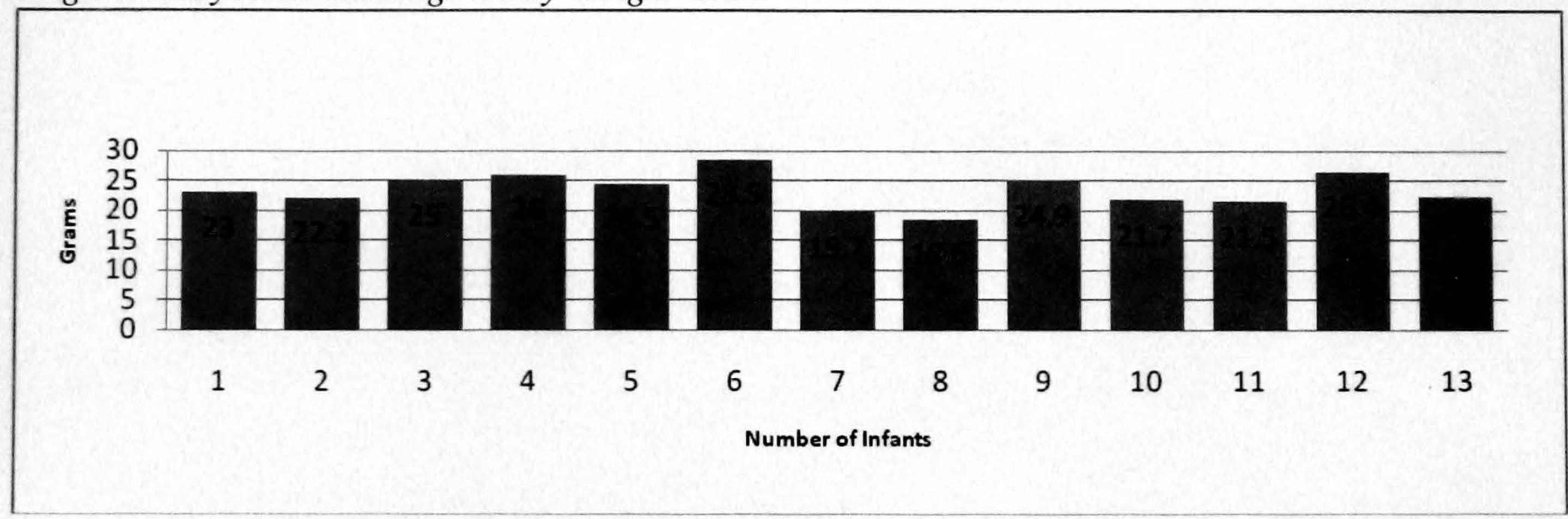

Table 3 illustrates a comparison of the average daily weight gain for those infants in the single family room (23.4 grams/day) compared to those infants in the multi-bed unit (20.2 grams/day). The infants in the single family room NICU gained an average of 3.2 grams/day more than those in the multi-bed unit.

\section{Table 3}

Average Daily Weight Gain Comparison, Single vs. Multi-Bed Unit

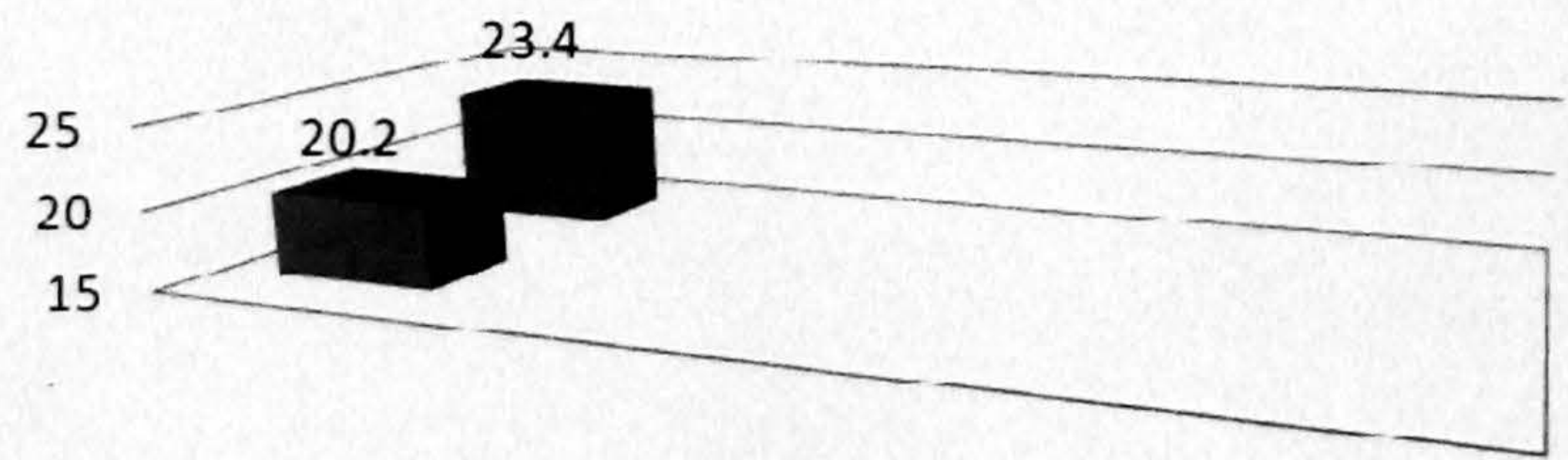

Multi-Bed Unit Single Family Room Unit 
Table 4 represents the average day of life that infants in the multi-bed NICU achieved full feedings. The average was day of life 27 , with a range of day of life 13 to day of life 53.

Table 4

\section{Multi-Bed Unit Achievement to Full Feedings}

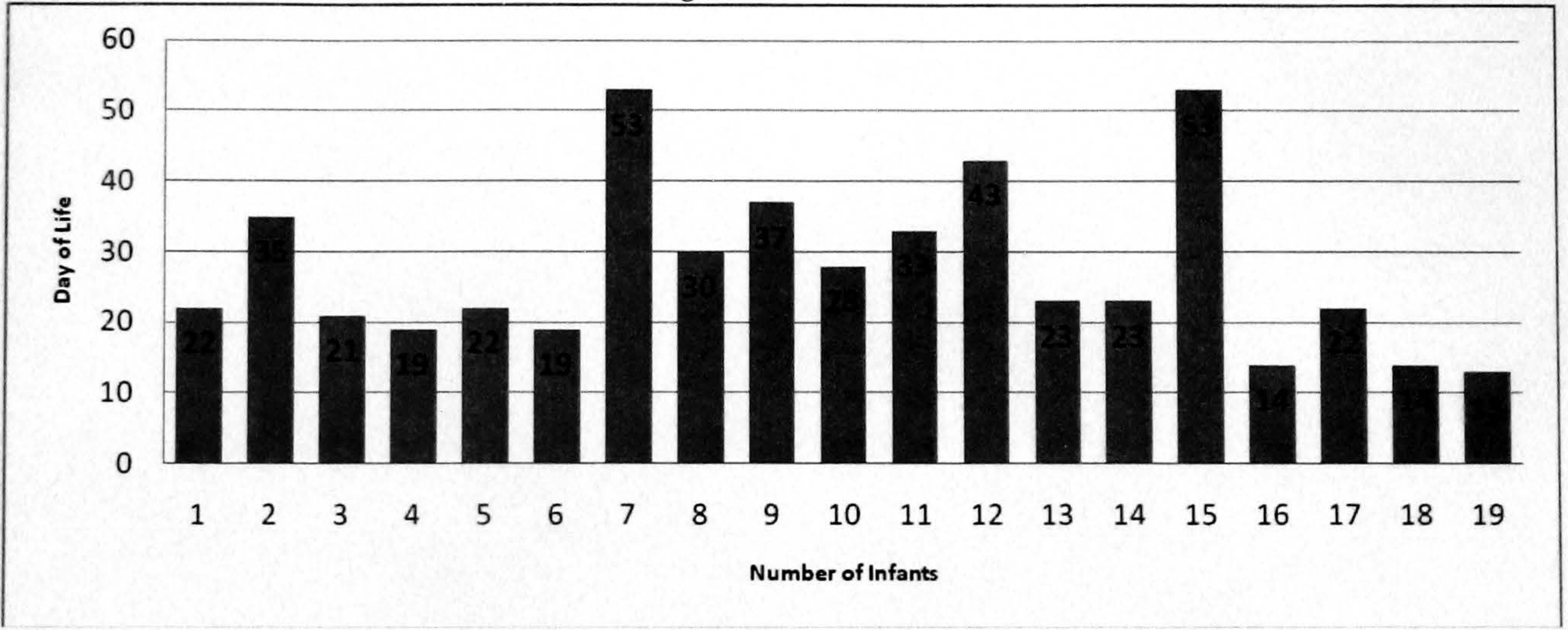

Table 5 illustrates the average day of life that infants in the single family room NICU achieved full feedings. The average was day of life 21 , with a range of day of life 10 to day of life 38 .

Table 5

Single Family Room Achievement to Full Feedings

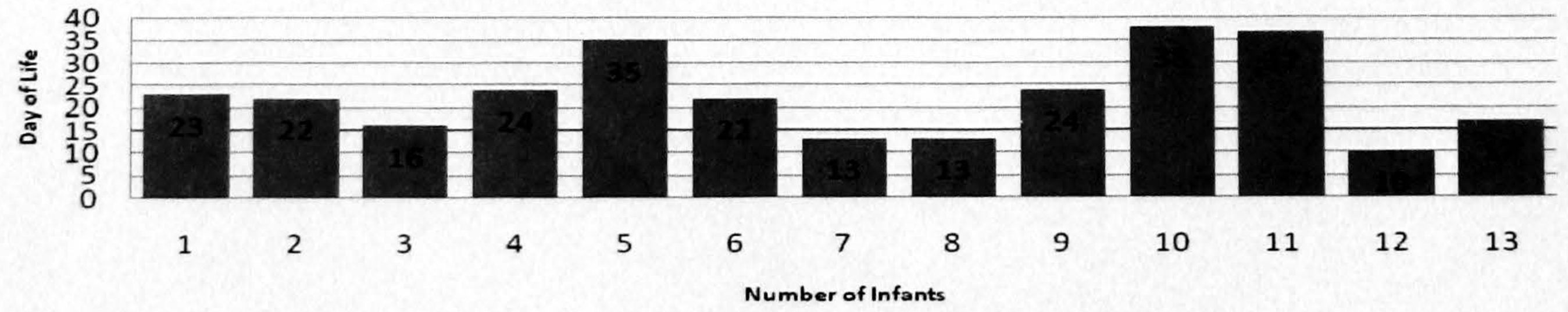


Table 6 shows a comparison of the average day of life for achievement of full feedings for those infants in the single family room (day of life 21) compared to those infants in the multi-bed unit (day of life 27).

Table 6

Comparison of Average Day of Life for Achievement of Full Feedings, Single vs. Multi-Bed Unit

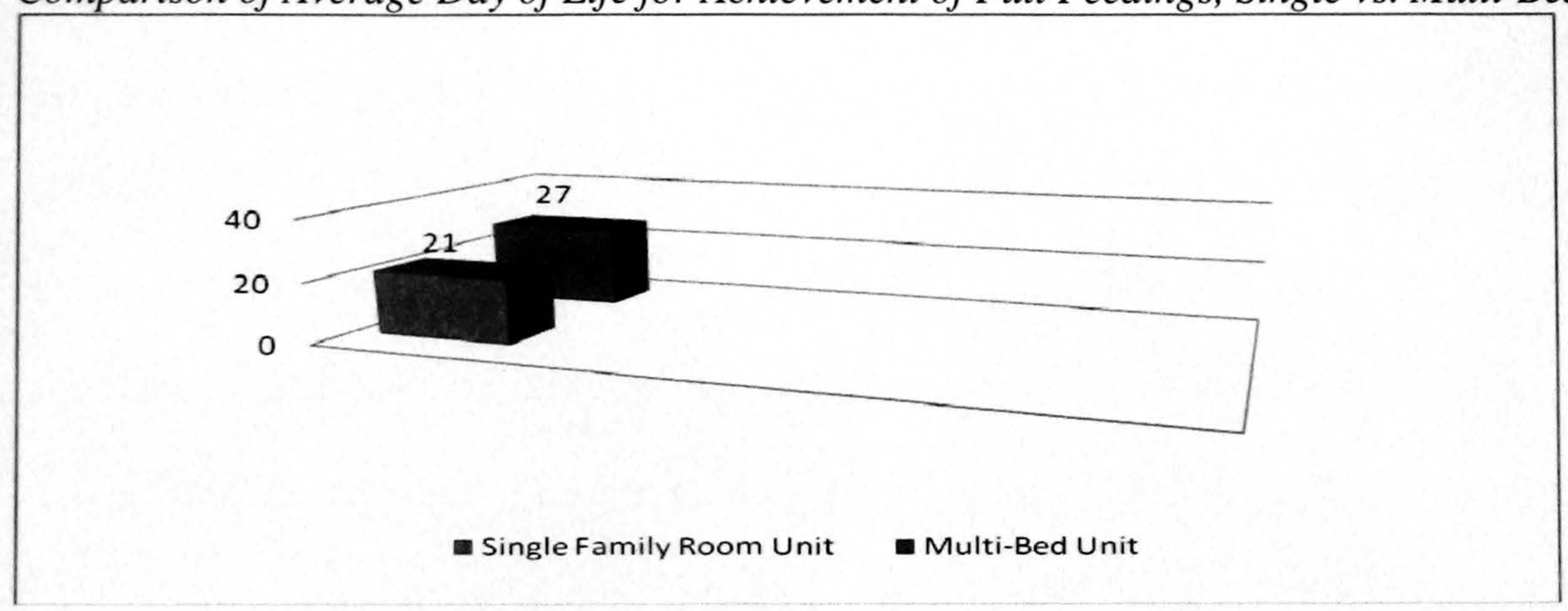

The research summary and conclusion will follow next. 


\section{Summary and Conclusion}

Many Neonatal ICUs are shifting their emphasis from a technology focused environment to an environment focused on parent involvement and decreased environmental stimuli by transitioning their design from multi-bed units to single family rooms. Literature reviewed for this research has been supportive of this transition, stating that the single family room unit provides increased family privacy, which supports breastfeeding and bonding, increased family participation in care, decreased noise, appropriately cycled lighting, and a potential for earlier increased weight gain. Most research also agreed that more research was necessary.

The purpose of this research study was to determine if a single family room NICU design directly impacted infant nutritional outcomes as measured by the average daily weight gain and achievement of full feedings for infants born less than 1000 grams. This study employed a retrospective, two group, quasiexperimental design. Results demonstrated a small difference in the average daily weight gain in the multibed NICU versus the single family room NICU. The average daily weight gain for the 19 infants in the multi-bed unit was 20.2 grams/day. The average daily weight gain for the 13 infants in the single-bed unit was 23.4 grams/day. These findings demonstrate a positive difference in average daily weight gain of 3.2 grams/day for those infants in the single-family unit design.

There was a remarkable difference in achievement of full feedings, with the single family room NICU infants advancing to full feedings six days earlier than those in the multi-bed unit. The average day of life for achievement of full feedings for those infants in the multi-bed unit was 27 as compared to 21 for those infants in the single family room unit. 
A significant limitation to this study was the small sample size from both the multi-bed unit and the single family room unit. As noted, there were over 55 infants eligible for the study; however, the exclusion criteria for this study included those infants over 1000 grams at birth, any infant requiring a surgical procedure, infants with major congenital anomalies, and those infants treated for feeding intolerance. For those infants in the single family room NICU the exclusion criteria included multiples, as they shared a common area. These exclusions were appropriate because surgical procedures, feeding intolerance, and multiples sharing the same room would have skewed the results for both groups. Either expanding the cohort groups to capture more infants or increasing the study time frame for both units would be useful to increase the study sample size without jeopardizing the significance of the study. Both the reliability and validity of the information provided was dependent upon proper documentation by providers and calculation accuracy.

Although this study was limited to infants born at less than 1000 grams, the evidence supports that a developmentally appropriate environment is important to feedings, weight gain, and an infant's overall health, which may decrease the length of stay and positively influence the family dynamics. Donabedian's theoretical framework supports the comparisons. Based upon the research conducted, it appears as though the structure and process have positively influenced the outcomes; therefore, we can conclude that the single family room environment positively impacts the daily weight gain and advancement to full feedings for infants weighing less than 1000grams at birth. 


\section{Recommendations and Implications for Advanced Nursing Practice}

It has been noted that increased visitation with infants in the NICU results in a better chance of recovery (Zeskind \& Iacino, 1984). The single family room design provides the parents and visitors an opportunity for increased visitation, bonding, and infant quiet time. Its' design facilitates family centered and developmentally supportive care. Family centered care in the single family room unit allows for and encourages the parents to stay overnight and participate in their baby's care and multidisciplinary rounds, where the plan of care is discussed.

A role of the APN is to foster research dissemination. It is the researcher's intention to disseminate the findings of this research to the NICU nursing staff and physicians. The APN could use this study as a basis for further research related to developmental care for infants cared for in the NICU. There are several implications for future research. Evidence that the single family room unit design influences variables such as sleep patterns, apnea and bradycardia, nosocomial infection, and feeding tolerance is needed. Another area necessitating further research is the cost-benefit analysis for both the hospital and insurance companies. Hospitals need to take building cost, reimbursement, and space allocation into consideration with restructuring a unit or building an addition to accommodate the extra space necessary to have a single family room unit. It is important to recognize that the single family room is ideal, but not always feasible. There are developmental care strategies that can be utilized in the multi-bed unit (such as ear muffs, lowering monitor alarms, and allowing parents to stay at the bedside for extended periods of time) that do not reproduce the single family room environment, but that can support developmentally appropriate care. The advanced practice nurse (APN) is prepared to research areas of interest and pursue studies in these areas. 
Although there is limited research available regarding the role of the advanced practice nurse in the NICU, the NICU setting can benefit from the knowledge and expertise that the APN can bring to care. The APN in the single family room design NICU has an opportunity to be an advocate for the family by encouraging and supporting them to take full advantage of the family-centered environment. Rooming in, Kangaroo care, and breastfeeding, all of which were nearly impossible for the parents to accomplish in the multi-bed unit due to lack of space and privacy, can now be accomplished. The APN and the multidisciplinary team are also able to conduct family meetings in a private setting without leaving the bedside. In fact, given that privacy and time constraints in the multi-bed unit are no longer a factor, the single family room units should be encouraged to consider adopting a policy of conducting multidisciplinary rounds when the parents are available, instead of vice-versa.

The APN as an expert clinician and role model should also educate the staff about the importance of completing the developmentally appropriate environment in the care they provide. For instance, often the nurse will complete her nursing assessment and the infant will fall back to sleep, then the provider will complete an assessment, and then the parents will take the baby out for care. The advanced practice nurse can also provide guidance to the staff by taking the opportunity to discuss the importance of clustering the infants care to allow the infant time for rest periods. Clustering care will also facilitate providers delivering their care based on the infants' behavioral cues rather than that of the providers' convenience. Any additional developmentally appropriate initiatives proposed and supported by the APN can also be addressed with the staff, such as recognizing and minimizing exposure to painful stimuli.

Nurses at Women and Infants Hospital have expressed concern that the transition to the single family room unit has isolated them from their colleagues, decreased the visibility of their patients, and increased 
the distance between them and their patients as compared to the multi-bed unit. These obstacles may present concerns with communication and the quality of care provided. The advanced practice nurse role is multifaceted, and, as a clinical expert, educator, and researcher, this leader can assist the staff of the single family room unit to work through these obstacles and provide quality, developmentally appropriate care to the infants while supporting the family and integrating them into the multidisciplinary team.

The APN, as a leader and integral part of the multidisciplinary team, is in a position to impact changes to current policy regarding care provided in the NICU. The advanced practice nurse could influence the quality of care provided in the NICU through policy-related changes to the orientation curriculum for the nursing staff and new residents/ medical providers. The APN could also impact policy by advocating for developmental initiatives such as clustered care.

From a community health perspective, the APN can provide support to the mother and infant dyad by promoting the opportunity for bonding and breastfeeding, which are critical to an infants' well being. The APN can serve as a liaison and critical link to the community in promoting health and wellness of mothers and their babies as well as in advocating for public policy supportive of these populations groups. The March of Dimes advocates for premature infants by conducting ongoing research and education. The APN can participate in their local Chapter and impact the community through research, education, and ongoing support. The APN can assist the March of Dimes in preventing preterm birth through increased community awareness of preterm birth risk factors and eliminating the health hazards that have been linked to preterm births. 


\section{References}

Ali, S. M., Sharma, J., Sharma, R., \& Alam, S. (2009). Kangaroo mother care as compared to conventional care for low birth weight babies. Dicle Tip Derg/Dicle Med J, 36(3), 155-160. Als, H., Duffy, F.H., McAnulty, G.B., Gibes-Grossman, R., \& Blickman, J.G. (1994). Individualized developmental care for the very low birthweight infant: medical and neurofunctional effects. Journal of the American Medical Association, 272, 853-858.

Belfort, M. (2006). Premature baby: Complications and concerns health article. Retrieved from http://www.healthline.com/yodocontent/pregnancy/preterm-delivery-premature-baby.html

Blackmore, C.A., \& Rowley, D.L. (2009). Preterm birth. Retrieved from http://www.cdc.gov/reproductivehealth/ProductsPubs/DatatoAction/pdf/birout2.pdf

Bloom, B. T., Mulligan, J., Arnold, C., Ellis, S., Moffitt, S., Rivera, A., . . Peabody, J., (2003). Improving growth of very low birth weight infants in the first 28 days. Pediatrics, $112(1), 8-14$.

Cattaneo, A., Davanzo, R., Worku, B., Surjono, A., Echeverria, M., Bedri, A., . . Tamburlini, G., (1998). Kangaroo mother care for low birth weight infants: a randomized controlled trial in different settings. Acta Paediatr, 87, 976-985.

CDC (2009). What do we know about tobacco use and pregnancy? Retrieved from

http://www.cdc.gov/reproductivehealth/tobaccouseduringpregnancy/index.htm

Donabedian, A. (1988). The quality of care: how can it be assessed? Journal of the American Medical Association, 12, 1743-1748.

Donabedian, A. (2003). An introduction to quality assurance in health care (Rev. ed.). New York : Oxford University Press. 
Floyd, A. D. (2005). Challanging designs of neonatal intensive care units. Critical Care Nurse, 25(5), 5965.

Freyer, F. (2009, December 28). Care, support may be best medicine for preventing premature births. The Providence Journal. Retrieved from http://www.projo.com/extra/2008/preemies/stories/part_six/index.html

Goldenberg, R., Culhane, J., Iams, J., \& Romero, R. (2008). Epidemiology and causes of preterm birth. The Lancet, 374(9606), 75-84.

Griffin, T. (2006). Family-centered care in the NICU. The Journal of Perinatal \& Neonatal Nursing , 20, 98-102.

Harrell, J. W., \& Moon, R. G. (2008). Designs for the delicate: A look at evolving NICU design standards. Health Facilities Management, , 45-48.

Hayakawa, M., Okumura, A., Hayakawa, F., Kato, Y., Ohshiro, M., Tauchi, N., . . Watanabe, K.,(2003). Nutritional state and growth and functional maturation of the brain in extremely low birth weight infants. Pediatrics, 111(5), 991-995.

Kunkel, S., Rosenqvist, U., \& Westerling, R. (2007). The structure of quality systems is important to the process and outcome, an emperical study of 386 hospital departments in Sweden. BMC Health Services Research, 7, 104. doi:10.1186/1472-6963-7-104

March of Dimes. (2009). Prematurity Awareness Month. Retrieved from http://marchofdimes.com Milford, C. A., Zapalo, B. J., \& Davis, G. (2008). Transition to an individual-room NICU design: Process and outcome measures. Neonatal Network, 27(5), 299-305. 
Pickler, R. H., Best, A., \& Crosson, D. (2009). The effects of feeding experience on clinical outcomes in preterm infants. Journal of Perinatology, 29, 124-129.

Rhode Island Kids Count Factbook. (2009). Retrieved from http://www.rikidscount.org/matriarch/documents/Preterm\%20Births\%202009.pdf

Spalding, K., \& McKeever, P., (1998). Mother's experiences caring for children with disabilities who require a gastrostomy tube. Journal of Pediatric Nursing, 13, 234-243.

St John, E.B., Nelson, K.G., Oliver, S.P., Bishnoi, R.R. \& Goldenberg, R.L. (2000) Cost of neonatal care according to gestational age at birth and survival status. Am Journal of Obstetrics and Gynecology; 182: $170-175$.

Swift, M. C., \& Scholten, I. (2009). Not feeding, not coming home: parental experiences of infant feeding difficulties and family relationships in a neonatal unit. Journal of Clinical Nursing, 19, 249-258.

Unknown. (2006). Preterm birth: causes, consequences, and prevention. Retrieved from http://www.iom.edu/Reports/2006/Preterm-Birth-Causes-Consequences-and-Prevention.aspx

Unknown (2007). Findings from the National Institute of Nursing Research related to neonatal care. Neonatal Network, 26(6), 414-417.

Walsh, W. F., McCullough, K. L., \& White, R. D. (2006). Room Improvement: Nurses' perceptions of providing care in a single room newborn intensive care setting. Advances in Neonatal Care, 6(5), 261-270.

White, R. D. (2003). Individual rooms in the NICU-an evolving concept. Journal of Perinatology, 23, S22S24. doi:10.1038/sj.jp. 72108402000 to 2005

White, R. D. (2007). Recommended standards for newborn ICU design. Retrieved from http://www.nd.edu/ nicudes/ 
Zeskind, P.\& Iacino, R. (1987). The relationship between length of hospitalization and the mental and physical development of preterm infants. Infant Behavior and Development ,10 (2), 217-221. 
Appendix A: Data Sheet

\begin{tabular}{|c|c|c|c|c|c|c|c|c|}
\hline $\begin{array}{c}\text { Patient } \\
\text { Identifier }\end{array}$ & DOB & $\begin{array}{c}\text { Discharge } \\
\text { date }\end{array}$ & $\begin{array}{c}\text { Birth } \\
\text { Weight } \\
\text { (grams) }\end{array}$ & $\begin{array}{c}\text { Discharge } \\
\text { Weight } \\
\text { (grams) }\end{array}$ & $\begin{array}{l}\text { Average daily } \\
\text { weight gain } \\
\text { (grams) }\end{array}$ & $\begin{array}{c}\text { Day of life full } \\
\text { feeds } \\
\text { achieved }\end{array}$ & $\begin{array}{r}\text { Wer } \\
\text { fe } \\
\text { achie } \\
\text { great } \\
72 \\
\end{array}$ & $\begin{array}{l}\text { full } \\
\text { ds } \\
\text { ed for } \\
\text { than } \\
?\end{array}$ \\
\hline 1 & & & & & & & $Y$ & $\mathbf{N}$ \\
\hline 2 & & & & & & & $Y$ & $\mathbf{N}$ \\
\hline 3 & & & & & & & $\mathbf{Y}$ & $\mathrm{N}$ \\
\hline 4 & & & & & & & $Y$ & $\mathbf{N}$ \\
\hline 5 & & & & & & & $\mathbf{Y}$ & $\mathbf{N}$ \\
\hline 6 & & & & & & & $\mathbf{Y}$ & $\mathbf{N}$ \\
\hline 7 & & & & & & & $Y$ & N \\
\hline 8 & & & & & & & $Y$ & $\mathbf{N}$ \\
\hline 9 & & & & & & & $\mathbf{Y}$ & $\mathrm{N}$ \\
\hline 10 & & & & & & & $Y$ & $\mathrm{~N}$ \\
\hline 11 & & & & & & & $Y$ & $\mathbf{N}$ \\
\hline 12 & & & & & & & $\mathbf{Y}$ & $\mathbf{N}$ \\
\hline 13 & & & & & & & $\mathbf{Y}$ & $\mathbf{N}$ \\
\hline 14 & & & & & & & $\mathbf{Y}$ & $\mathbf{N}$ \\
\hline 15 & & & & & & & $\mathbf{Y}$ & $\mathbf{N}$ \\
\hline 16 & & & & & & & $\mathbf{Y}$ & $\mathbf{N}$ \\
\hline 17 & & & & & & & $Y$ & $\mathbf{N}$ \\
\hline 18 & & & & & & & $\mathbf{Y}$ & $\mathbf{N}$ \\
\hline 19 & & & & & & & $\mathbf{Y}$ & $\mathbf{N}$ \\
\hline 20 & & & & & & & $Y$ & $\mathrm{~N}$ \\
\hline 21 & & & & & & & $\mathbf{Y}$ & $\mathbf{N}$ \\
\hline 22 & & & & & & & $Y$ & $\mathbf{N}$ \\
\hline 23 & & & & & & & $\mathbf{Y}$ & $\mathbf{N}$ \\
\hline 24 & & & & & & & $\mathbf{Y}$ & $\mathbf{N}$ \\
\hline
\end{tabular}

